\title{
An integral topical gel for cellulite reduction: results from a double-blind, randomized, placebo-controlled evaluation of efficacy
}

This article was published in the following Dove Press journal:

Clinical, Cosmetic and Investigational Dermatology

20 February 2014

Number of times this article has been viewed

\section{Eric Dupont ${ }^{\prime}$ \\ Michel Journet ${ }^{2}$ \\ Marie-Laure Oula ${ }^{3}$ \\ Juan Gomez' \\ Claude Léveillé ${ }^{4}$ \\ Estelle Loing ${ }^{5}$ \\ Diane Bilodeau ${ }^{6}$}

'Immanence IDC Inc, Québec, QC, Canada; ${ }^{2}$ Clinique de Dermatologie St-Joseph, Montréal, QC, Canada ${ }^{3}$ Evalulab Inc, Mont-Royal, QC,

Canada; ${ }^{4} \mathrm{Clinique}$ de Chirurgie Esthétique du Québec Métropolitain, Lévis, QC, Canada; ${ }^{5}$ Lucas Meyer Cosmetics, Québec, QC, Canada; ${ }^{6}$ CosmeConsult, Québec, QC, Canada
Correspondence: Diane Bilodeau

CosmeConsult, 174, 9e Rue,

Québec, QC GIL 2NI, Canada

Tel + I 4l8353 II06

Fax +I 4186584622

Email diane.bilodeau@cosmeconsult.com
Background: Cellulite is a serious cosmetic concern for most of the $90 \%$ of women affected by it.

Objective: To assess the clinical efficacy of a complex integral anti-cellulite gel.

Methods: This double-blind, randomized, placebo-controlled study involved 44 healthy women, aged 25-55 years. Subjects had a normal to slightly overweight body mass index and presented slight to moderate cellulite on their thighs, buttocks, and/or hips at baseline. Subjects were randomly assigned to either the treated or placebo group and accordingly applied the active product or placebo on their hips, stomach, buttocks, and thighs, twice daily for 3 months. Skin tonicity, orange-peel aspect, and stubborn cellulite were assessed at day $0,28,56$, and 84 . A self-evaluation questionnaire was completed by all volunteers.

Results: At the end of the study, an average of $81 \%$ of the subjects applying the active product presented improvement in their cellulite condition versus $32 \%$ for the placebo group (all descriptors and sites combined). At day 84, skin tonicity, orange-peel appearance, and stubborn cellulite were improved in a significant manner $(P<0.05)$ over placebo, on all studied areas. Skin tonicity improved on average by $+41 \%$ for buttocks, $+35 \%$ for hips, and $+31 \%$ for thighs. Orange peel appearance was reduced on average by $-25 \%$ for buttocks, $-22 \%$ for hips, and $-22 \%$ for thighs. Stubborn cellulite was reduced on average by $-19 \%$ for buttocks, $-24 \%$ for hips, and $-22 \%$ for thighs. Circumference measurements decreased in a significant manner $(P<0.05)$ over placebo, for the abdomen (average value of $-1.1 \mathrm{~cm}$ ) and thighs (average value of $-0.8 \mathrm{~cm}$ ). The product was well tolerated and perceived by the volunteers themselves as better performing than placebo on all criteria.

Conclusion: All results validate the efficacy of the present integral formulation to significantly reduce signs of cellulite and reshape the silhouette.

Keywords: orange-peel appearance, skin tonicity, circumference reduction, clinical trial

\section{Introduction}

Cellulite refers to a local alteration of the relief of the skin which acquires an orangepeel, or mattress, appearance. The orange-peel appearance results from the bulging of fat lobules out of their connective frame, into the dermis. The phenomenon is most commonly seen on hips, buttocks, and thighs but can also touch other areas, including the abdomen. Up to $90 \%$ of woman, over 20 years of age, are affected at various degrees, against only $2 \%$ of men. ${ }^{1-3}$ Cellulite is seen as a normal condition by the medical community, but it is a serious cosmetic concern for most women affected by it.

Although cellulite involves fat cells, it is not a manifestation of obesity, and even young women with a normal body mass index (BMI) may get it. ${ }^{4}$ However, being overweight aggravates the presence of cellulite. Other risk factors include a predisposing 
genetic background, hormonal imbalance, medication that causes water retention, a sedentary lifestyle, prolonged periods of immobility, wearing tight clothes, smoking, excessive alcohol intake, unhealthy eating habits, stress, and being Caucasian. ${ }^{5}$ Some disorders have also been associated with cellulite, such as venous insufficiency, kidney problems, metabolic perturbations, and gastrointestinal alterations. ${ }^{5}$

The exact etiology of cellulite is still a matter of debate, but most scientists will agree on the involvement of reduced microcirculation, interstitial liquid infiltration (edema), localized hypertrophy of adipocytes, oxidative stress, and persistent low grade inflammation, combined with extracellular matrix alterations., ${ }^{4,6-9}$ The extensibility, elasticity, and resilience of the skin are also abnormal. ${ }^{10}$ Figure 1 schematizes all these elements. The condition may start with hormone-induced activation of matrix-metalloproteinases (MMPs), which weakens capillary walls and challenges extracellular matrix integrity. ${ }^{11}$ As a result, fluid leaks out of vessels, and inflammatory cells are recruited within tissues where they generate inflammation and release additional MMPs. In an effort to heal, the damaged matrix of the septa becomes fibrosclerotic. ${ }^{7}$ Meanwhile, hormones may also stimulate the metabolic activity of adipocytes, which increase in volume. Hypertrophic fat lobules tend to exert pressure on the surrounding capillaries, therefore adding to their fragility and hampering circulation. ${ }^{10}$

The process is a reminder of what happens with aging in the upper layers of skin (dermis and epidermis) where changes are associated with MMP activation, altered biomechanical properties, reduced vessel integrity, and inflammation. Indeed, a clinical study conducted by Ortonne et $\mathrm{al}^{12}$ confirmed that the presence of cellulite precipitates skin aging in women over 30 years of age. Therefore, it may be advisable to address both conditions simultaneously when treating cellulite. The approach described in this paper follows this lead. The test product is an integral gel, simultaneously addressing skin aging and cellulite. The patent-pending ${ }^{13}$ formula combines all active cosmetic ingredients listed in Table 1. The final concentration of cosmetic active ingredients in the formulation reaches $25 \%$ (weight per weight [w/w]).

The skin anti-aging aspect of the formulation integrates multiple ingredients addressing all major known mechanisms involved in the process. The components, rationale, and efficacy of this anti-aging approach have been described previously elsewhere. ${ }^{14}$ For their part, the anti-cellulite ingredients were selected on the basis of their potential complementarities in addressing the cellulite problem on all fronts, according to published literature. They include cosmetic ingredients with well documented anti-cellulite activity, such as caffeine, retinol, forskolin (Coleus forskohlii), sacred lotus (Nelumbo nucifera), carnitine, and escin, among others. For a list of all ingredients present in the formulation and their respective expected action on skin, please refer to Table 1.

Many of the ingredients included in this formulation have proven their anti-cellulite efficacy in published human clinical studies. For instance, caffeine is a known stimulator

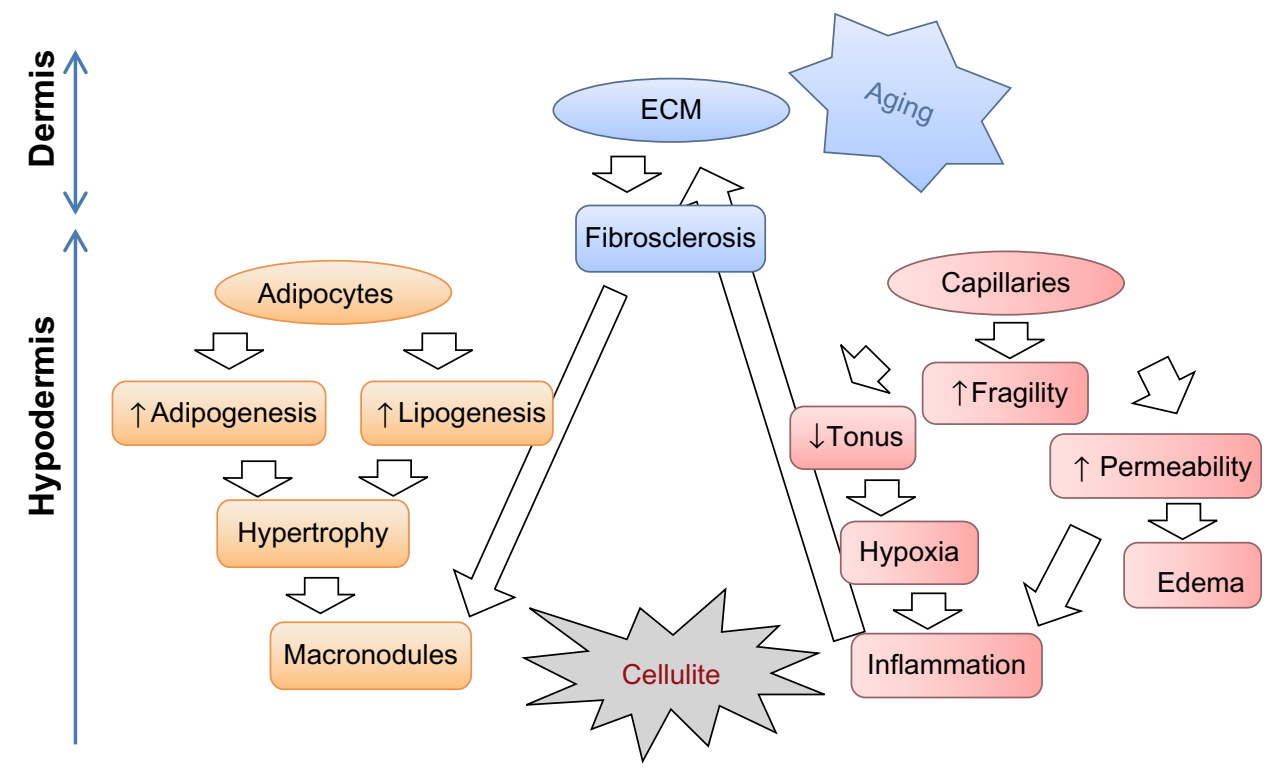

Figure I Major mechanisms involved in cellulite. The exact etiology of cellulite is still a matter of debate but most scientists agree on the involvement of reduced microcirculation, interstitial liquid infiltration (edema), localized hypertrophy of adipocytes, oxidative stress, and persistent low grade inflammation, combined with ECM alterations. Cellulite and skin aging may influence each other.

Abbreviation: ECM, extracellular matrix. 
of lipolysis, through inhibition of phosphodiesterase and increased adenosine monophosphate levels in adipocytes, ${ }^{2}$ and has had its slimming activity clinically confirmed by Lupi et al. ${ }^{15}$ As is the case for the present formulation, caffeine may be vectorized with phospholipids to facilitate skin absorption. ${ }^{16}$ As was done here, caffeine may also be mixed with other active ingredients for improved performance. Indeed, a mixture of caffeine and $N$. nucifera extract was shown by Escudier et al to enhance the benefits of a healthy diet for the treatment of cellulite. ${ }^{17}$ A synergistic mixture including caffeine, carnitine, forskolin, and retinol was also reported by Roure et $\mathrm{al}^{18}$ to improve several parameters linked to cellulite. Moreover, a mixture of retinol, caffeine, and ruscogenin was able to reduce the orange-peel appearance and increase microcirculation in a clinical study reported by Bertin et al. ${ }^{19}$ Single ingredients, also found in this formulation have documented anti-cellulite activity as well. This is the case for retinol, which by itself, improves skin thickness in patients with cellulite, as demonstrated clinically by Kligman et al, ${ }^{20}$ while Piérard-Franchimont et $\mathrm{al}^{21}$ reported effects on tensile properties of skin, in the context of cellulite. Acting to strengthen capillaries and limit edema when applied topically, escin, derived from horse chestnut, is another ingredient of the current gel that has found application in anti-cellulite formulations..$^{22,23}$

The aim of the present study was to assess the clinical efficacy of a multi-active integral anti-cellulite gel, in comparison with a vehicle placebo gel, on a panel of human volunteers. Both products were evaluated and compared for their effect on tonicity, orange-peel aspect, stubborn cellulite, and their potential for reduction in circumference of areas affected by cellulite, over a period of 84 days.

\section{Materials and methods Products}

The test product (from Immanence IDC Inc, Québec, QC, Canada) and the placebo (vehicle only) were supplied as gels of similar appearance and texture. Upon receipt by the testing laboratory, the samples were blindly assigned a code, before being stored at ambient humidity and temperature, in their original container. The active formulation contained several cosmetic actives selected on the basis of their potential to address all major mechanisms generally recognized as being involved in the development of cellulite (see Introduction and Table 1 for more details). The total concentration of cosmetic active ingredients in the formulation reached $25 \%(\mathrm{w} / \mathrm{w})$. The placebo contained the exact formulation as the testing product, only without the active ingredients listed in Table 1, and consisted of a basic gel containing mainly water, jellifying agents, and preservatives.

\section{Subjects}

Forty-four healthy women, aged 25-55 years (mean age of 39.8 years), were recruited for this study. Twenty-two subjects (mean age of 39.1 years) were randomly assigned to the active product group, while the other 22 (mean age of 40.2 years) formed the placebo group. All subjects presented slight to moderate cellulite on their thighs, buttocks, and/or hips, at baseline. The subjects had a normal to slightly overweight BMI of between 20.0 and $28.0 \mathrm{~kg} \mathrm{~m}^{-2}$ and agreed to maintain their usual diet and level of physical activity throughout the study. People having taken, within 7 days of study start, medication, treatment, or natural products that could affect the outcome of the study, were excluded from the present protocol. Participants were asked to refrain from applying other anti-cellulite treatments, cosmetic products, or moisturizers to the studied areas for the duration of the study. Participants were neither allowed to receive additional massage treatment, nor to use any massage accessory during the whole length of the study. Participants were also instructed not to take medication or health supplements capable of affecting bodyweight for the length of the study.

\section{Study design}

The current study No 12F-0201 was a randomized, parallelgroup, double-blind, placebo-controlled study, with one group assigned to the active gel and one group assigned to a placebo gel. Neither the participants nor the evaluators were aware of the nature (active or placebo) of the product being individually used. Subjects were instructed to apply the gel (active or placebo) on their hips, stomach, buttocks, and thighs, on a clean and dry skin, and to gently massage, with the palm only, until complete skin penetration. The procedure was repeated twice a day (morning and evening) for a total of 84 consecutive days (12 weeks). Clinical evaluation was performed in a laboratory room under controlled temperature $\left(22^{\circ} \mathrm{C} \pm 3^{\circ} \mathrm{C}\right)$ and relative humidity $(30 \% \pm 5 \%)$, at day 0 (baseline), day 28 (week 4), day 56 (week 8), and day 84 (week 12). The weight of each volunteer was also recorded at each visit to determine their BMI and assess their compliance with protocol. The clinical data obtained at each time-point were compared with baseline for each group and also between groups in the search for statistically relevant differences. A self-assessment questionnaire was filled in on day 14 (week 2), day 28 (week 4), and day 84 (week 12) to document the subjects' own subjective 


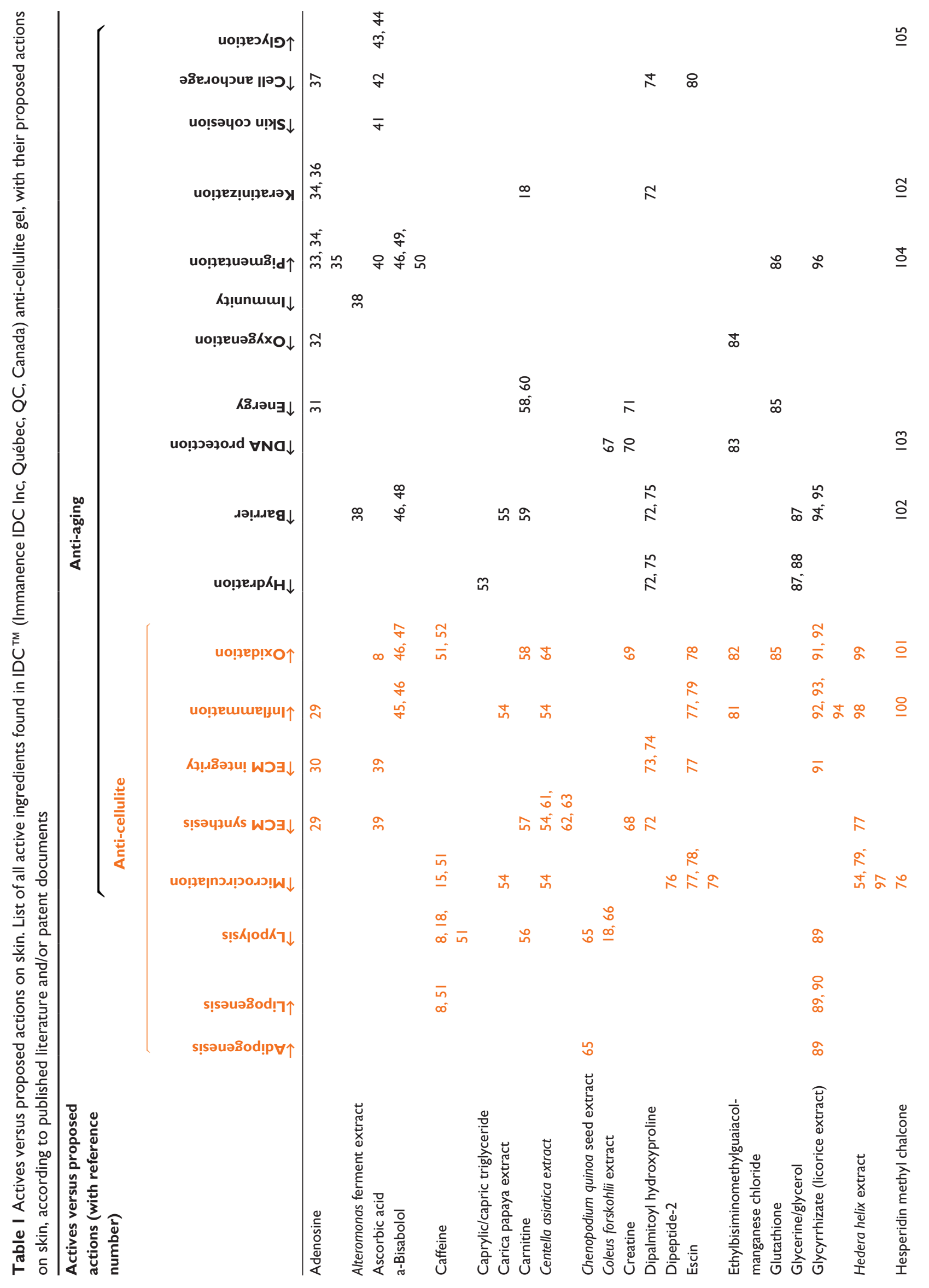




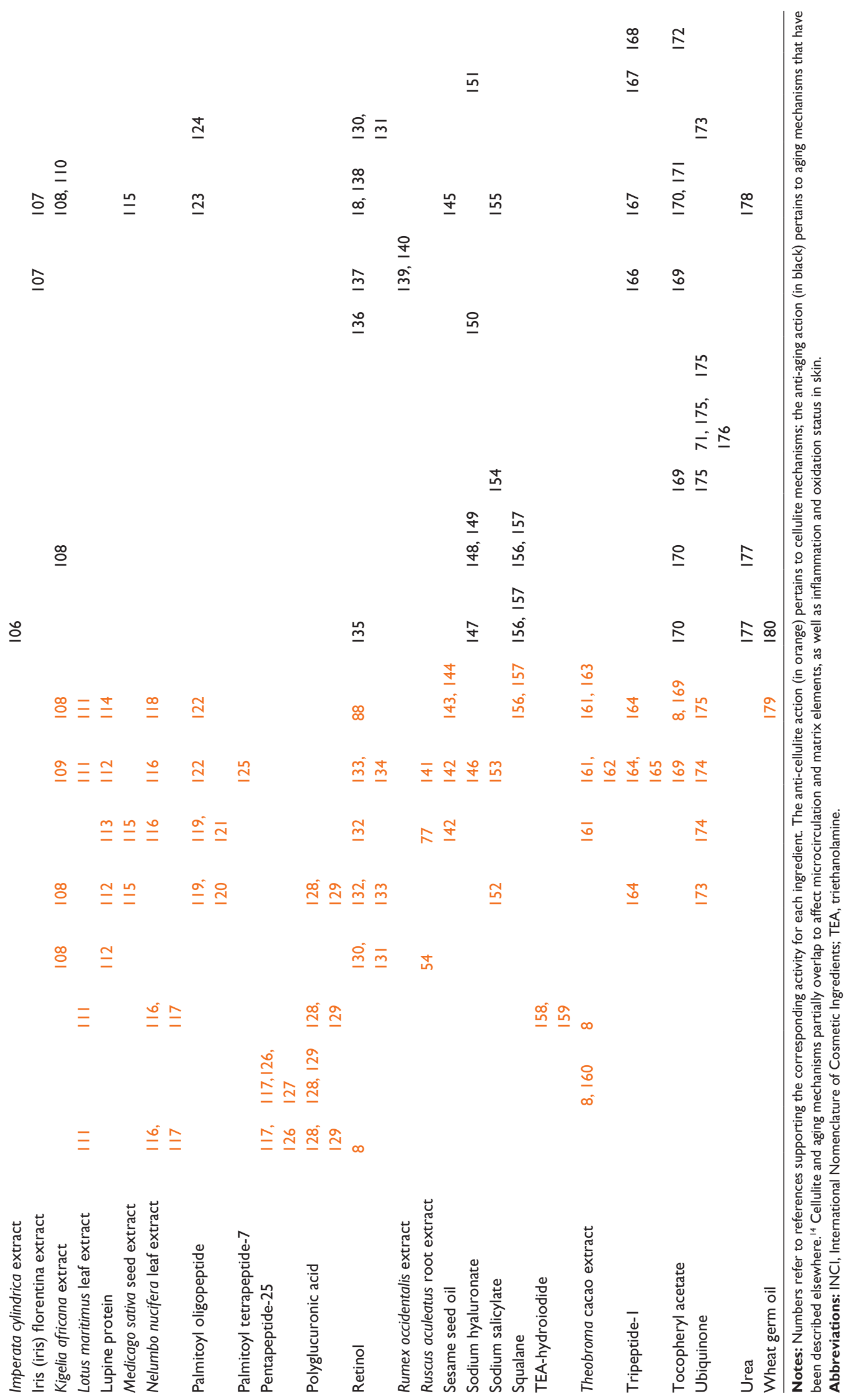


perception of product efficacy. The full detailed protocol is available from the sponsor of the study (Immanence IDC Inc).

\section{Study location}

The study took place in Montréal, Canada, from the end of February to the end of May, for a total of 84 consecutive days (12 weeks) following first application of the product. The study was conducted by an independent contract testing laboratory specialized in claim validation for cosmetic products, under the control of a dermatologist. The testing laboratory was responsible for the selection and randomization of all participants, as well as the gathering and statistical analysis of results.

\section{Clinical assessment}

\section{Evaluation of skin tonicity}

Skin tonicity was assessed using an analogical scale developed by the testing laboratory responsible for clinical evaluation of the product. For this purpose, a tubular device was designed and filled with layers of foam of increasing density in order to reproduce variations in skin tonicity, on a scale ranging from 1 "minimum firmness" to 7 "maximum firmness" (Figure 2). Grading of tonicity was performed by comparing the resistance of skin versus the resistance of this dedicated foam-like device, when applying a constant pressure with fingers. The repeatability and reproducibility of the procedure was validated by applying analysis of variance. In the present study, grading was performed by the same

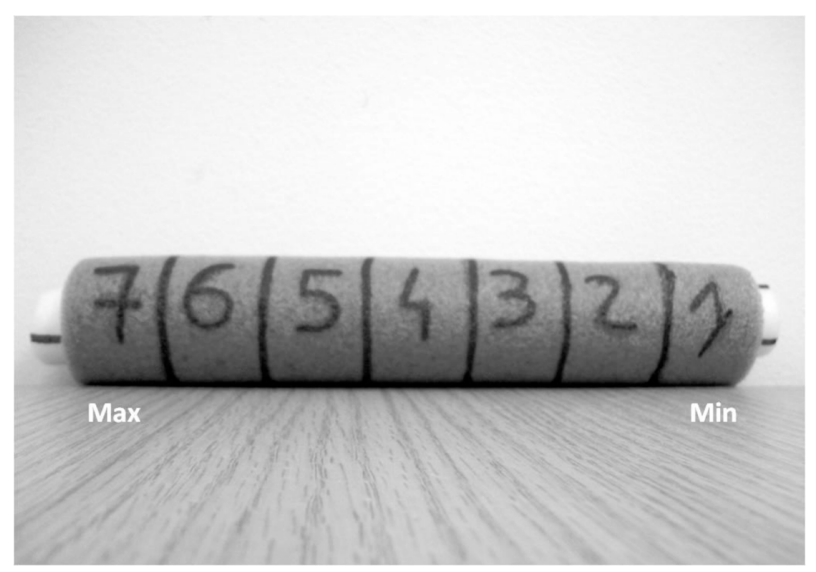

Figure 2 Device for grading skin tonicity. The tubular device is filled with layers of foam of increasing density in order to reproduce variations in skin tonicity, on a scale ranging from I "minimum firmness" to 7 "maximum firmness." Grading is performed by comparing the resistance of skin versus the resistance of this dedicated foamlike device, when applying a constant pressure with fingers. The repeatability and reproducibility of the procedure has been validated by applying analysis of variance. Abbreviations: Max, maximum; Min, minimum. trained technician, on a precisely localized area of interest on hips, buttocks, and thighs.

\section{Evaluation of cellulite appearance}

"Orange peel" aspect on relaxed skin and "stubborn cellulite" on pinched skin (thighs and hips) or on contracted buttocks were assessed using an analogical validated scale (from 0 "no intensity" to 8 "maximum intensity") on hips, buttocks, and thighs (Figure 3). The scale used in the present study was an adaptation of a scale initially developed by Hexel et al. ${ }^{24}$ Orange peel and stubborn cellulite evaluation were performed by the same trained technician at each visit, in the same room (under controlled conditions of lighting, temperature, and humidity), and on the same body areas of interest for each subject, with the volunteer standing in a standardized upright position (ground references for feet repositioning).

Each measurement site was localized precisely, with the help of a graduated rule and a laser beam to determine the site position with respect to the ground and ensure a correct vertical positioning. For reproducibility, the length of the laser beam was recorded at the first visit, and the same length was used at all subsequent visits. Additionally, a mapping of the skin's surface features (eg, brown spots and scars) for each measurement site on each volunteer was recorded in order to precisely reposition during subsequent measurements.

\section{Circumference measurements}

Circumference measurements were obtained using a measuring tape, with the volunteers standing in a standardized upright position. Each measurement site was localized precisely, with the help of a graduated rule and a laser beam to determine the site position with respect to the ground and ensure a correct vertical positioning. For reproducibility, the length of the laser beam was recorded at the first visit, and the same length was used at all subsequent visits. Additionally, a mapping of the skin's surface features (eg, brown spots and scars) for each measurement site on each volunteer was recorded in order to precisely reposition during subsequent measurements. The circumference of the following sites was measured: abdomen (2-3 cm below the navel), hips/buttocks, and both thighs (in the middle).

\section{Qualitative survey}

Treatment efficacy was also qualitatively assessed through a survey. The self-evaluation questionnaire was designed to gauge volunteers' perception of the overall performance of 


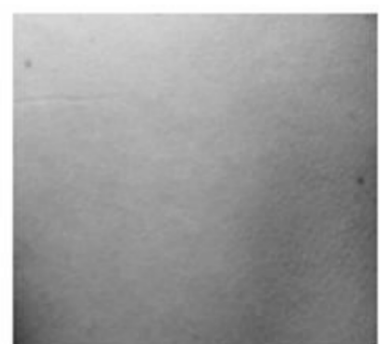

Grade 0

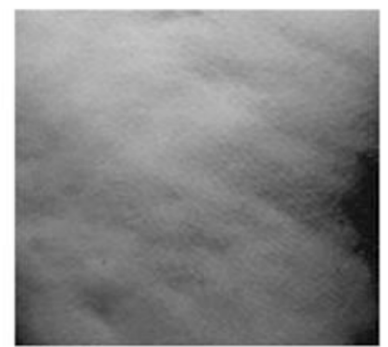

Grade 3

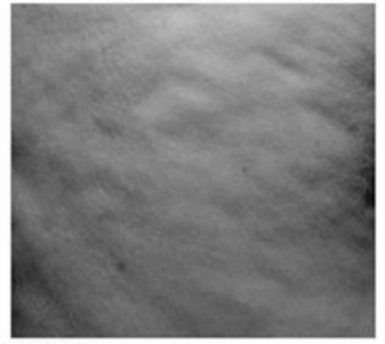

Grade 6

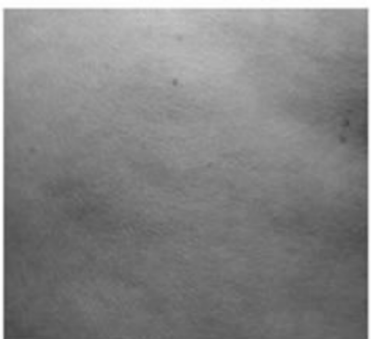

Grade 1

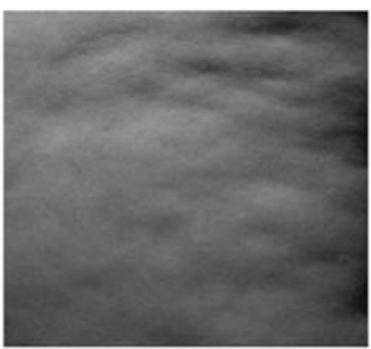

Grade 4

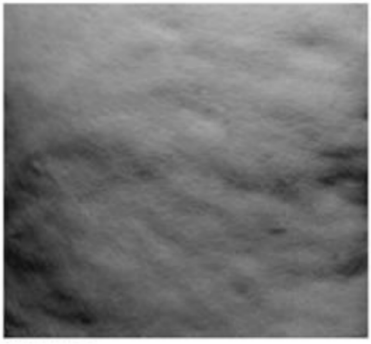

Grade 7

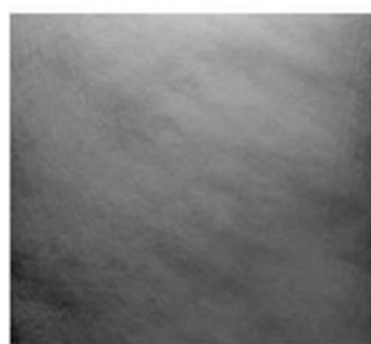

Grade 2

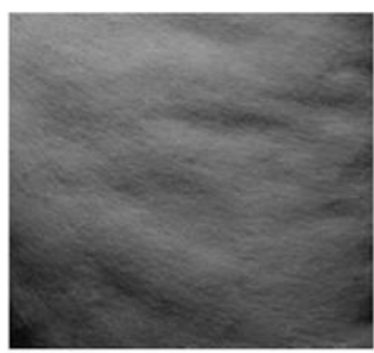

Grade 5

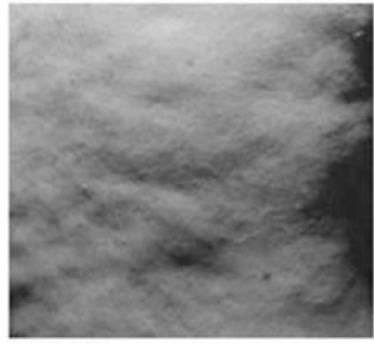

Grade 8

Figure 3 Visual grading scale for orange-peel appearance. The scale goes from 0 "no intensity" to 8 "maximum intensity."

products (active or placebo). All subjects were requested to fill in a questionnaire pertaining to skin firmness and smoothness on day 14 (week 2), as well as reduction of cellulite, attenuation of "orange skin" appearance, and improvement of skin texture on day 28 (week 4) and day 84 (week 12) of product application. Additionally, volunteers were asked to evaluate the perceived slimming effect after 84 days of twice-daily treatment. For a list of all evaluation criteria, please refer to Table 2 .

\section{Statistical analysis}

Statistical analysis was carried out on all pertinent parameters. Results obtained at day 28,56 , and 84 for both treatments (test product and placebo) were compared with baseline results (day 0) using the Student's $t$-test (paired two-sample $t$-test for means), allowing the evaluation of the effect of each treatment. Whenever appropriate, results were expressed as the mean of measurements obtained from all volunteers within each group. All relevant anti-cellulite results were noted and analyzed using a hypothesis test (two-sample $t$-test, assuming equal or unequal variance), allowing the comparison of the mean value of both groups at day 28 (week 4), day 56 (week 8), and day 84 (week 12), in order to determine whether there was any significant difference between the two treatments.

Table 2 Questionnaire and schedule for self-evaluation of product efficacy

\begin{tabular}{|c|c|}
\hline Schedule & Criteria \\
\hline \multirow[t]{2}{*}{ Week 2 (day I4) } & My skin seems smoother \\
\hline & My skin seems firmer \\
\hline \multirow[t]{4}{*}{ Week 4 (day 28) } & The texture of my skin has improved (at touch) \\
\hline & My skin seems firmer \\
\hline & The "orange peel" appearance is attenuated \\
\hline & The signs of cellulite are visibly reduced \\
\hline \multirow[t]{9}{*}{ Week 12 (day 84) } & The texture of my skin has improved (at touch) \\
\hline & My skin seems firmer \\
\hline & The "orange peel" appearance is attenuated \\
\hline & The signs of cellulite are visibly reduced \\
\hline & My skin seems more hydrated \\
\hline & My skin silhouette seems reshaped \\
\hline & My skin silhouette seems svelter \\
\hline & I feel like I have less water retention \\
\hline & My skin looks more radiant \\
\hline
\end{tabular}




\section{Ethics}

The standard procedure and associated documents were reviewed and approved by the ethics committee of Evalulab Inc. prior to commencement of the clinical trial. The ethics committee was an independent organization whose members' responsibility was to ensure the protection of the rights, security, and wellbeing of the volunteers participating in the study. Written informed consent was obtained from all participants prior to any trial procedure. This study was conducted in accordance with the ethical standards formulated in the 1964 Declaration of Helsinki and its later amendments.

\section{Results}

\section{Participants}

Of the 44 volunteers initially recruited, 40 completed the study. Two participants from each group (active and placebo) did not complete the study, the reason being unanticipated schedule incompatibilities. The remaining 40 volunteers completed the study without any adverse event and were included in the statistical analysis of the results by original assigned groups.

\section{Efficacy results \\ Bodyweight evolution}

The BMI of all volunteers did not vary significantly throughout the study. For the active product group, the average BMI was $24.8 \mathrm{~kg} \mathrm{~m}^{-2}$ at day 0 and $28,24.6 \mathrm{~kg} \mathrm{~m}^{-2}$ at day 56 , and $24.7 \mathrm{~kg} \mathrm{~m}^{-2}$ at day 84 . For the placebo group, the average BMI was $24.5 \mathrm{~kg} \mathrm{~m}^{-2}$ at day $0,24.7 \mathrm{~kg} \mathrm{~m}^{-2}$ at day $28,24.6 \mathrm{~kg} \mathrm{~m}^{-2}$ at day 56 , and $24.5 \mathrm{~kg} \mathrm{~m}^{-2}$ at day 84 . Therefore, it is considered that all participants adhered to the protocol by maintaining their weight and lifestyle.

\section{Evaluation of skin tonicity}

After 84 days of twice-daily treatment the active gel significantly $(P<0.05)$ improved skin tonicity, over baseline, on all studied areas (Figure 4). When compared with baseline, results reached average values of $+9 \%$ at day $28,+39 \%$ at day 56 , and $+41 \%$ at day 84 on the buttocks. For hips, results gave average values of $+10 \%$ at day $28,+17 \%$ at day 56 , and $+35 \%$ at day 84 . For thighs, results were on average $+9 \%$ at day $28,+17 \%$ at day 56 , and $+31 \%$ at day 84 . Placebo treatment resulted in limited improvement of skin tonicity (Figure 4).

At day 84 , statistical analysis $(P<0.05)$ on all studied areas demonstrated that the active gel was better performing than placebo at increasing skin tonicity (Figure 4). Also, at the end of the study, a larger number of subjects presented improvement in skin tonicity when applying the active product, compared with placebo (95\% versus $55 \%$ on thighs, $70 \%$ versus $40 \%$ on hips, and $70 \%$ versus $30 \%$ on buttocks) (Table 3 ).

\section{Evaluation of orange-peel appearance}

After 84 days of product use, treatment with the active gel significantly $(P<0.05)$ reduced the orange-peel appearance
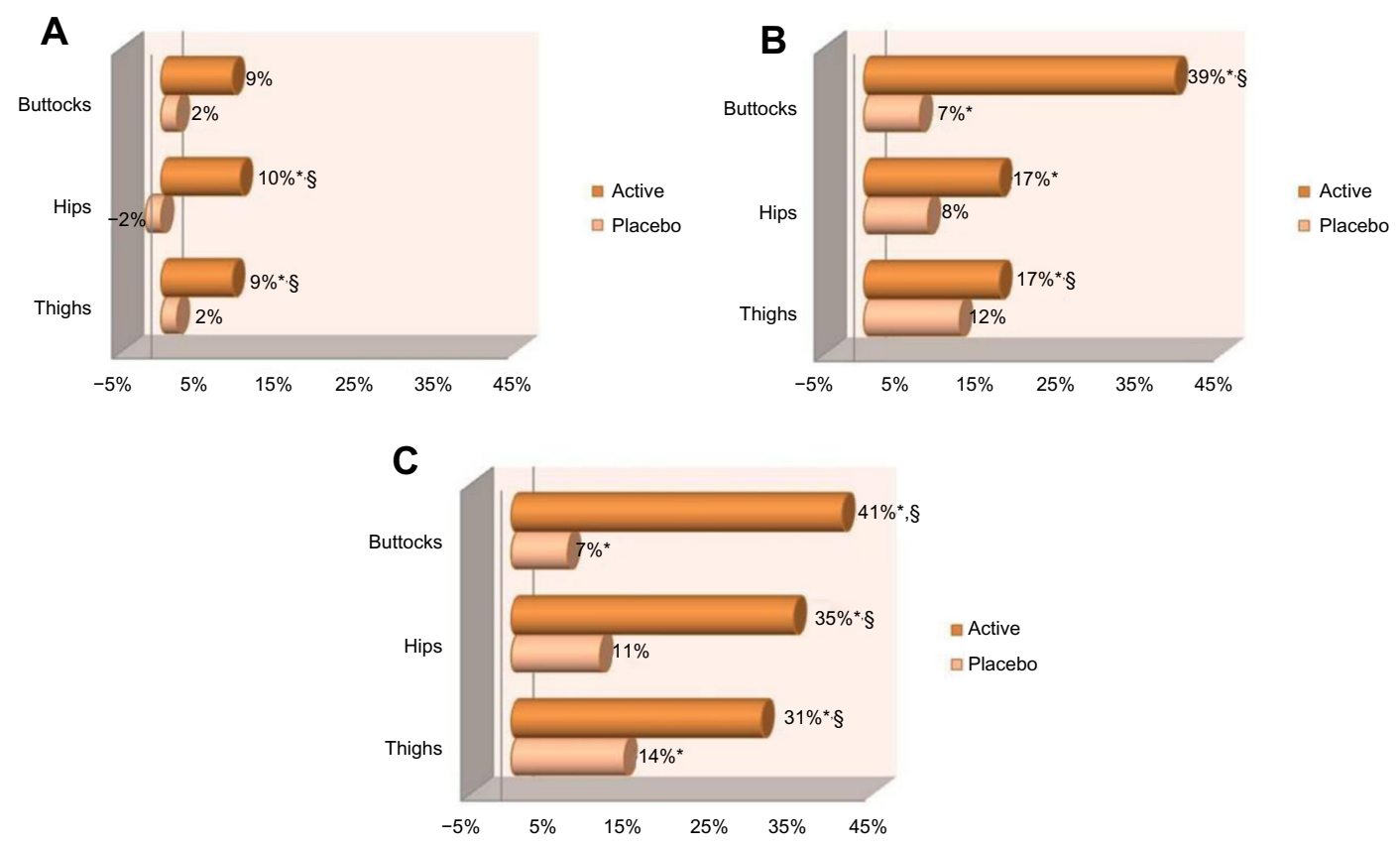

Figure 4 Means of the evolution of skin tonicity at (A) day 28, (B) day 56, and (C) day 84 for both treated and placebo groups.

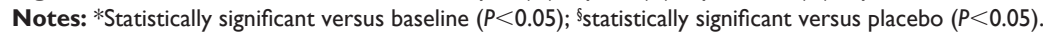


Table 3 Percentage of volunteers with improvement at the end of the study (day 84)

\begin{tabular}{|c|c|c|c|c|c|c|c|c|}
\hline \multirow{2}{*}{$\begin{array}{l}\text { Zone } \\
\text { Group }\end{array}$} & \multicolumn{2}{|l|}{ Thighs } & \multicolumn{2}{|l|}{ Hips } & \multicolumn{2}{|c|}{ Buttocks } & \multicolumn{2}{|l|}{ Mean } \\
\hline & Active & Placebo & Active & Placebo & Active & Placebo & Active & Placebo \\
\hline Tonicity & $95 \%$ & $55 \%$ & $70 \%$ & $40 \%$ & $70 \%$ & $30 \%$ & $78 \%$ & $42 \%$ \\
\hline Orange peel & $95 \%$ & $40 \%$ & $65 \%$ & $10 \%$ & $80 \%$ & $20 \%$ & $80 \%$ & $23 \%$ \\
\hline Stubborn cellulite & $95 \%$ & $40 \%$ & $75 \%$ & $20 \%$ & $85 \%$ & $35 \%$ & $85 \%$ & $32 \%$ \\
\hline Mean & $95 \%$ & $45 \%$ & $70 \%$ & $23 \%$ & $78 \%$ & $28 \%$ & $81 \%$ & $32 \%$ \\
\hline
\end{tabular}

of the skin (no pinching), over baseline, on all studied areas (Figure 5). When compared with baseline, results obtained for buttocks reached average values of $-9 \%$ at day $28,-16 \%$ at day 56 , and $-25 \%$ at day 84 . For thighs, results were on average $-5 \%$ at day $28,-11 \%$ at day 56 , and $-22 \%$ at day 84 . For hips, results gave average values of $-8 \%$ at day 56 and $-22 \%$ at day 84 . Placebo treatment resulted in limited improvement of orange-peel appearance (Figure 5).

At day 84 , statistical analysis $(P<0.05)$ on all studied areas demonstrated that treatment with the active gel was better performing at reducing the orange-peel appearance than placebo treatment (Figure 5). Also, at the end of the study, a larger number of subjects presented improvement in orange-peel appearance when applying the active gel, compared with placebo (95\% versus $40 \%$ on thighs, $65 \%$ versus $10 \%$ on hips, and $80 \%$ versus $20 \%$ on buttocks) (Table 3 ).

\section{Evaluation of stubborn cellulite appearance}

After 84 days of product use, treatment with the active gel significantly $(P<0.05)$ reduced stubborn cellulite (with pinching), over baseline, on all studied areas (Figure 6). When compared with baseline, results obtained for hips gave average values of $-6 \%$ at day $28,-17 \%$ at day 56 , and $-24 \%$ at day 84 . For thighs, the average values were $-6 \%$ at day $28,-15 \%$ at day 56 , and $-22 \%$ at day 84 . For buttocks, the average values were $-9 \%$ at day $28,-15 \%$ at day 56 , and $-19 \%$ at day 84 . Placebo treatment resulted in limited improvement of stubborn cellulite (Figure 6).

At day 84 , statistical analysis $(P<0.05)$ on all studied areas demonstrated that treatment with the active gel was better performing at reducing stubborn cellulite than placebo treatment (Figure 6). Also, at the end of the study, a larger number of subjects presented improvement in stubborn cellulite appearance when applying the active gel, compared with placebo (95\% versus $40 \%$ on thighs, $75 \%$ versus $20 \%$ on hips, and $85 \%$ versus $35 \%$ on buttocks) (Table 3 ).

\section{Circumference measurements}

After 84 days of product use, treatment with the active gel significantly $(P<0.05)$ reduced, over baseline, the circumference
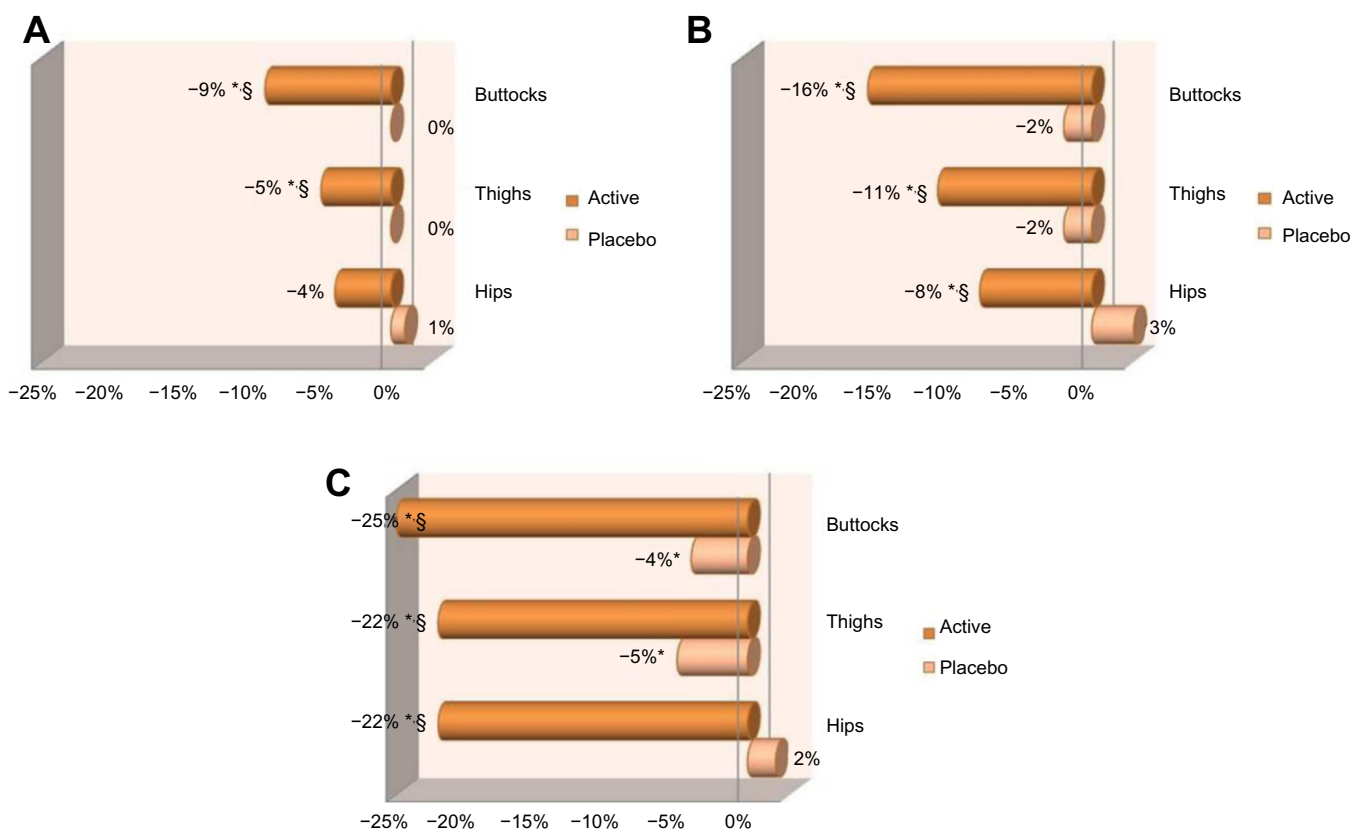

Figure 5 Means of the evolution of orange-peel appearance at (A) day 28, (B) day 56, and (C) day 84 for both treated and placebo groups. Notes: *Statistically significant versus baseline $(P<0.05)$; ${ }^{\S}$ statistically significant versus placebo $(P<0.05)$. 

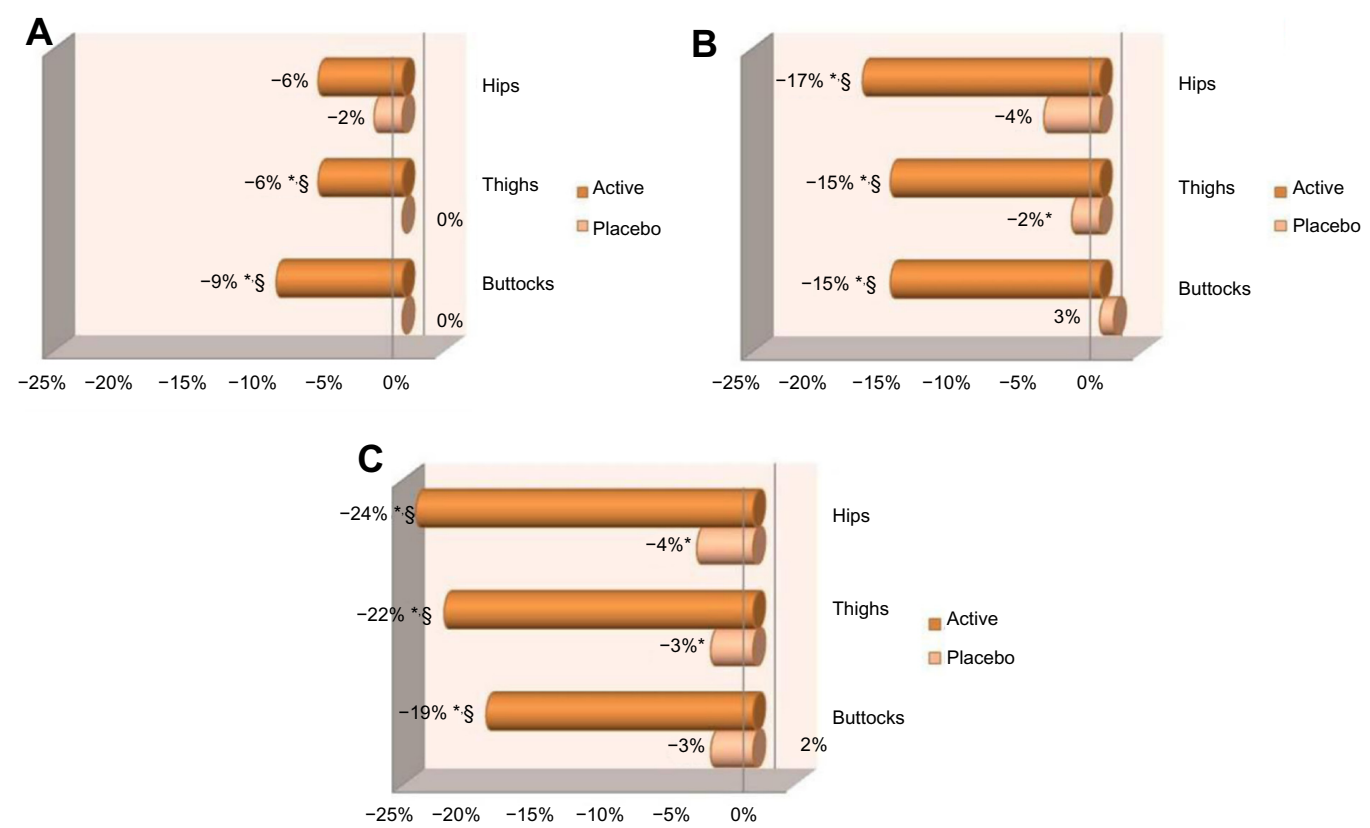

Figure 6 Means of the evolution of stubborn cellulite (with pinching) at (A) day 28, (B) day 56, and (C) day 84 for both treated and placebo groups. Notes: *Statistically significant versus baseline $(P<0.05)$; §statistically significant versus placebo $(P<0.05)$.

of all studied areas. When compared with baseline, results obtained for the abdomen gave average values of $-0.4 \mathrm{~cm}$ at day $28,-0.9 \mathrm{~cm}$ at day 56 , and $-1.1 \mathrm{~cm}$ at day 84 . For the right thigh, the average values were $-0.3 \mathrm{~cm}$ at day $28,-0.6 \mathrm{~cm}$ at day 56 , and $-0.8 \mathrm{~cm}$ at day 84 . For the left thigh, the average values were $-0.1 \mathrm{~cm}$ at day $28,-0.4 \mathrm{~cm}$ at day 56 , and $-0.8 \mathrm{~cm}$ at day 84 . For buttocks, the average values were $-0.4 \mathrm{~cm}$ at day $28,-0.7 \mathrm{~cm}$ at day 56 , and $-0.8 \mathrm{~cm}$ at day 84 (Table 4 ). Placebo treatment resulted in limited improvement of circumference measurements (Table 4).

At day 84 , statistical analysis $(P<0.05)$ demonstrated that treatment with the active gel was better performing than placebo at reducing the circumference of the abdomen and thigh areas (Table 4). Also, at the end of the study, a larger number of subjects presented a reduction in circumference measurements on all studied areas when applying the active

Table 4 Means of the evolution (Dx-D0) of circumference measurements (in $\mathrm{cm}$ )

\begin{tabular}{|c|c|c|c|c|c|c|}
\hline Time & Day 28 & & Day 56 & & Day 84 & \\
\hline Product & Active & Placebo & Active & Placebo & Active & Placebo \\
\hline Abdomen & $-0.4^{*}$ & -0.2 & $-0.9 *, \S$ & -0.2 & $-\mid . I^{*, \delta}$ & $-0.4^{*}$ \\
\hline Right thigh & -0.3 & 0.0 & $-0.6 *$ & -0.3 & $-0.8^{*, \S}$ & -0.3 \\
\hline Left thigh & -0.1 & 0.0 & $-0.4^{*}$ & -0.2 & $-0.8^{*, \delta}$ & -0.3 \\
\hline $\begin{array}{l}\text { Hips/ } \\
\text { buttocks }\end{array}$ & -0.4 & -0.1 & $-0.7^{*}$ & -0.2 & $-0.8^{*}$ & $-0.4^{*}$ \\
\hline
\end{tabular}

Notes: *Statistically significant versus baseline $(P<0.05)$; ${ }^{\S}$ statistically significant versus placebo $(P<0.05)$. gel, compared with placebo ( $80 \%$ versus $35 \%$ on the abdomen, $45 \%$ versus $35 \%$ on the right thigh, and $70 \%$ versus $35 \%$ on the left thigh) (results not shown).

\section{Qualitative survey}

The overall scores for perceived performance of the test product (active gel or placebo) collected from the selfevaluation questionnaires completed by all volunteers are presented in Figure 7.

At day 14 and 28, statistical analysis of the data did not demonstrate any significant difference between the two groups in the perception of treatment efficacy.

At the end of the study (day 84), statistical analysis showed that the active gel performed significantly better than the placebo, on the following parameters (Figure 7).

- Firmness: $85 \%$ versus $45 \%(P<0.05)$

- Orange peel appearance: $65 \%$ versus $25 \%(P<0.05)$

- Silhouette seems more svelte: $45 \%$ versus $15 \%$ $(P<0.05)$

At day 84 , results reached near significance on the following parameters (Figure 7).

- Silhouette seems reshaped: $50 \%$ versus $20 \%(P<0.1)$

- Less water retention: $40 \%$ versus $15 \%(P<0.1)$

- Signs of cellulite are visibly reduced: $55 \%$ versus $30 \%$ $(P<0.1)$

No statistical difference was observed for the other parameters. 

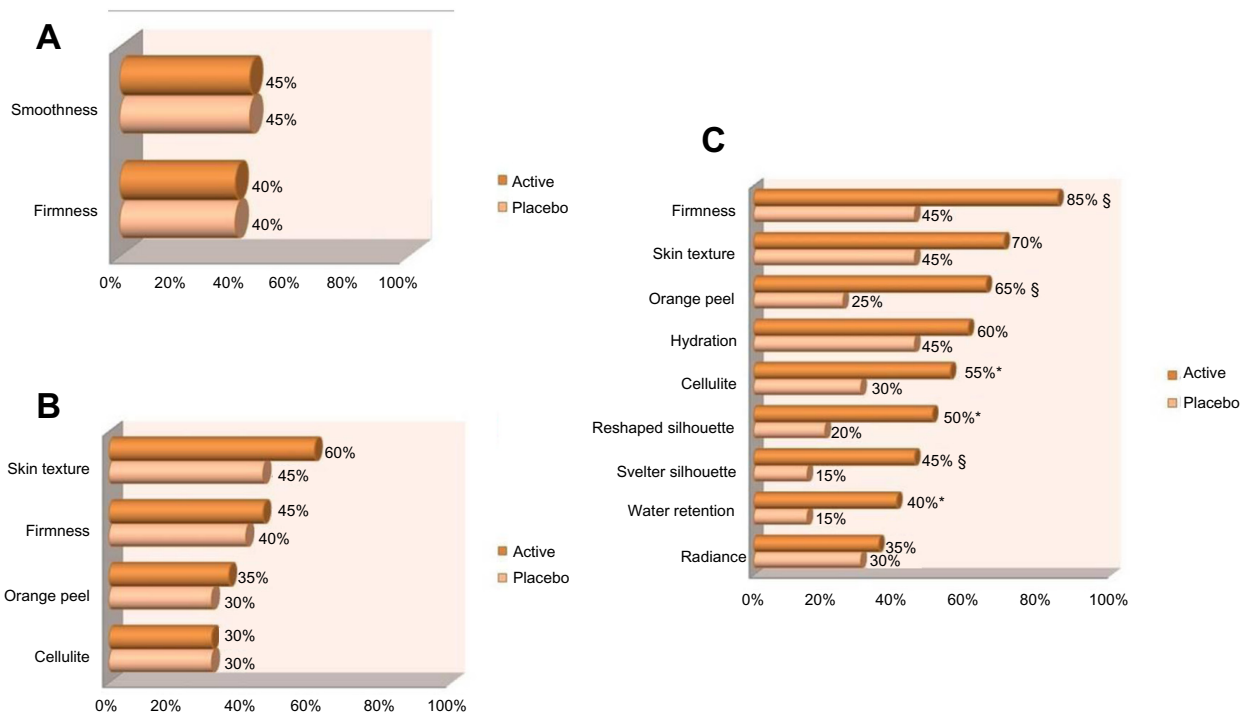

Figure 7 Means of the evolution of self-perception of product efficacy at (A) day 14, (B) day 28, and (C) day 84 for both treated and placebo groups. Notes: *Statistically significant versus baseline $(P<0.05)$; ${ }^{\text {s }}$ tatistically significant versus placebo $(P<0.05)$.

\section{Discussion}

The present study was rigorously designed on a pharmaceutical model. This was a double-blind, parallel group, randomized, placebo-controlled study. The study establishes the efficacy of the test product (from Immanence IDC Inc) to improve the appearance of cellulite and reduce the circumference of the affected areas. At the end of the study period, statistical analysis on all pertinent parameters clearly demonstrated significant performance superiority for the active product over placebo. The test product was a gel integrating several cosmetic active ingredients (listed in Table 1) selected on the basis of their potential to address all major mechanisms generally recognized as being involved in the development of cellulite (Figure 1 and Table 1), according to published literature and/or patent documents. The formulation also covers all major skin aging mechanisms,${ }^{14}$ since skin aging and cellulite may influence each other, ${ }^{12}$ as outlined in the Introduction.

By the end of the clinical trial (day 84), following twicedaily application of the test product, all studied parameters relating to cellulite, including skin tonicity, orange-peel appearance, and stubborn cellulite, were statistically improved over placebo $(P<0.05)$ on all studied areas, ie, buttocks, thighs, and hips. Results obtained for skin tonicity reached average values of $+41 \%$ for buttocks, $+35 \%$ for hips, and $+31 \%$ for thighs. Results obtained for orangepeel appearance (no pinching) reached average values of $-25 \%$ for buttocks, $-22 \%$ for hips, and $-22 \%$ for thighs. Results obtained for stubborn cellulite (with pinching or on contracted buttocks) reached average values of $-19 \%$ for buttocks, $-24 \%$ for hips, and $-22 \%$ for thighs. For the treated group, benefits were already seen on all parameters by day 28 , improving constantly over time until the end of the study. The absence of a plateau effect suggests that the full potential for improvement had not been reached within 84 days (12 weeks) of twice-daily application of the test product, and that further amelioration might be seen with longer application periods.

At the end of the study (day 84), an average of $81 \%$ of the subjects applying the active gel presented improvement in their cellulite condition versus $32 \%$ for the placebo group (all descriptors and sites combined). The slight benefits obtained with the placebo gel are most likely related to a massaging effect upon application of the gel. Massaging is known to impact positively on cellulite appearance possibly by improving microcirculation and drainage in the affected area. ${ }^{25}$ In support of that, a combination of mechanical and manual lymphatic drainage has been reported to reduce body measurements in areas with cellulite. ${ }^{26}$ However, in the present study, the potential benefits from massaging are expected to be comparable for both groups since the placebo and treatment products contained the exact same gel base, had similar rheological characteristics, and were applied in the same manner.

The effect of the product on the appearance of the silhouette was assessed through circumference measurements of the abdomen, thighs, and hips/buttocks areas. By the end of the study (day 84), a significant reduction in circumference 
was observed over placebo $(P<0.05)$ for the abdomen (mean of $-1.1 \mathrm{~cm}$ ) and for both thighs (mean of $-0.8 \mathrm{~cm}$ ). Again, limited benefits were obtained with the placebo gel; we believe this to reflect the contribution of massaging upon application. Importantly, all volunteers maintained a constant BMI throughout the study, attesting that the reduction in circumference and remodeling effects were not due to weight loss but most likely to better fluid drainage of the cellulite-affected areas and possibly also through a reduction in aging symptoms.

Treatment efficacy was also evaluated by the volunteers themselves. As could be expected, there was no difference in efficacy perception between the active product and the placebo group at day 14. Cellulite is a complex condition that cannot improve rapidly. However, slight differences between the two groups started emerging at day 28 , and were neatly confirmed at day 84 , with better performance for the active product over placebo. This progression in efficacy perception mirrors the progression documented through trained specialist evaluation. At the end of the study, statistically significant difference $(\Delta \%)$ in terms of criteria appreciation between groups was seen for skin firmness, orange-peel appearance, and reshaped silhouette (Figure 7).

\section{Conclusion}

All results validate the efficacy of the present integral formulation to significantly reduce the signs of cellulite and reshape the silhouette, but do not provide information on the performance of individual ingredients within it. Cellulite is a complex phenomenon that requires a complex approach, and it is likely that no single ingredient is solely responsible for the benefits reported here. In support of this, synergistic action of anti-cellulite ingredients has been described in the literature previously. ${ }^{17-19,27,28}$ In fact, a multi-target/multicomponent strategy is increasingly seen as the best approach to improve the appearance of cellulite.

Another limitation of the present study comes from the fact that it does not allow evaluating the contribution of anti-aging actives, found in the formulation, to the overall anti-cellulite effects. This could be the subject of future studies. The concept of fighting the appearance of cellulite by including both anti-aging and anti-cellulite actives in one integral formula is an interesting and promising approach that certainly deserves a closer look.

Yet another limitation of the study is linked to the fact that it was stopped before any plateau effect was reached. The maximum efficacy of the gel remains unknown, as well as its sustainability in time. More prolonged studies may be advisable in the future when assessing the effect of anticellulite products.

Nevertheless, the clear anti-cellulite beneficial effects of the blend of actives tested here support the use of a combination of ingredients exploiting different mechanisms of action and complementarily working to improve the condition.

\section{Disclosure}

ED owns Immanence IDC Inc (Québec, QC, Canada), the company that provided the test product and funded this research. JG is employed by the sponsor company, and DB is a paid consultant for the sponsor company. The other authors report no conflicts of interest in this work.

\section{References}

1. Emanuele E, Bertona M, Geroldi D. A multilocus candidate approach identifies ACE and HIF1A as susceptibility genes for cellulite. $J$ Eur Acad Dermatol Venereol. 2010;24(8):930-935.

2. Rawlings AV. Cellulite and its treatment. Int J Cosmet Sci. 2006;28(3): 175-190.

3. Mirrashed F, Sharp JC, Krause V, Morgan J, Tomanek B. Pilot study of dermal and subcutaneous fat structures by MRI in individuals who differ in gender, BMI, and cellulite grading. Skin Res Technol. 2004;10(3): 161-168.

4. Kruglikov I. The pathophysiology of cellulite: can the puzzle eventually be solved? J Cosmet Dermatol Sci Appl. 2012;2(1):1-7.

5. Rossi AB, Vergnanini AL. Cellulite: a review. J Eur Acad Dermatol Venereol. 2000;14(4):251-262.

6. Terranova F, Berardesca E, Maibach H. Cellulite: nature and aetiopathogenesis. Int J Cosmet Sci. 2006;28(3):157-167.

7. Khan MH, Victor F, Rao B, Sadick NS. Treatment of cellulite: Part I. Pathophysiology. J Am Acad Dermatol. 2010;62(3):361-370.

8. Hexsel D, Soirefmann M. Cosmeceuticals for Cellulite. Semin Cutan Med Surg. 2011;30(3):167-170.

9. de la Casa Almeida M, Suarez Serrano C, Rebollo Roldán J, Jiménez Rejano JJ. Cellulite's aetiology: a review. J Eur Acad Dermatol Venereol. 2013;27(3):273-278.

10. Draelos ZD. The disease of cellulite. J Cosmet Dermatol. 2005;4(4): 221-222.

11. Pugliese PT. The pathogenesis of cellulite: a new concept. J Cosmet Dermatol. 2007;6(2):140-142.

12. Ortonne JP, Zartarian M, Verschoore M, Queille-Roussel C, Duteil L. Cellulite and skin aging: is there any interaction? J Eur Acad Dermatol Venereol. 2008;22(7):827-834.

13. Dupont E, Samson M, Galderisi A, inventors; Immanence Integral Dermo Correction Inc, assignee. Skin care compositions and method of use thereof. United States patent US 20110158922. June 30, 2011.

14. Dupont E, Gomez J, Léveillé C, Bilodeau D. From hydration to cell turnover: an integral approach to anti-aging. Cosmet Toiletries. 2010;125(3):50-60.

15. Lupi O, Semenovitch IJ, Treu C, Bottino D, Bouskela E. Evaluation of the effects of caffeine in the microcirculation and edema on thighs and buttocks using the orthogonal polarization spectral imaging and clinical parameters. J Cosmet Dermatol. 2007;6(2):102-107.

16. Kim C, Shim J, Han S, Chang I. The skin-permeation-enhancing effect of phosphatidylcholine: caffeine as a model active ingredient. J Cosmet Sci. 2002;53(6):363-374.

17. Escudier B, Fanchon C, Labrousse E, Pellae M. Benefit of a topical slimming cream in conjunction with dietary advice. Int J Cosmet Sci. 2011;33(4):334-337. 
18. Roure R, Oddos T, Rossi A, Vial F, Bertin C. Evaluation of the efficacy of a topical cosmetic slimming product combining tetrahydroxypropyl ethylenediamine, caffeine, carnitine, forskolin and retinol, In vitro, ex vivo and in vivo studies. Int J Cosmet Sci. 2011;33(6):1-8.

19. Bertin C, Zunino H, Pittet JC, et al. A double-blind evaluation of the activity of an anti-cellulite product containing retinol, caffeine, and ruscogenine by a combination of several non-invasive methods. J Cosmet Sci. 2001;52(4):199-210.

20. Kligman AM, Pagnoni A, Stoudemayer T. Topical retinol improves cellulite. J Dermatolog Treat. 1999;10(2):119-125.

21. Piérard-Franchimont C, Piérard GE, Henry F, Vroome V, Cauwenbergh G. A randomized, placebo-controlled trial of topical retinol in the treatment of cellulite. Am J Clin Dermatol. 2000;1(6):369-374.

22. Sirtori CR. Aescin: pharmacology, pharmacokinetics and therapeutic profile. Pharmacol Res. 2001;44(3):183-193.

23. Incandela L, Belcaro G, Nicolaides AN, Geroulakos G, Cesarone MR, De Sanctis MT. Microcirculation after standardized application of Essaven gel on normal skin - a placebo-controlled, randomized study. Angiology. 2001;52 Suppl 3:S5-S10.

24. Hexsel D, Dal'forno T, Hexsel CL. A validated photonumeric cellulite severity scale. J Eur Acad Dermato Venereol. 2009;23(5):523-528.

25. Bayrakci Tunay V, Akbayrak T, Bakar Y, Kayihan H, Ergun N. Effects of mechanical massage, manual lymphatic drainage and connective tissue manipulation techniques on fat mass in women with cellulite. J Eur Acad Dermatol Venereol. 2010;24(2):138-142.

26. de Godoy JM, de Godoy Mde F. Treatment of cellulite based on the hypothesis of a novel physiopathology. Clin Cosmet Investig Dermatol. 2011;4:55-59.

27. Al-Bader T, Byrne A, Gillbro J, et al. Effect of cosmetic ingredients as anticellulite agents: synergistic action of actives with in vitro and in vivo efficacy. J Cosmet Dermatol. 2012;11(1):17-26.

28. Vogelgesang B, Bonnet I, Godard N, Sohm B, Perrier E. In vitro and in vivo efficacy of sulfo-carrabiose, a sugar-based cosmetic ingredient with anti-cellulite properties. Int J Cosmet Sci. 2011;33(2):120-125.

29. Valls MD, Cronstein BN, Montesinos MC. Adenosine receptor agonists for promotion of dermal wound healing. Biochem Pharmacol. 2009;77(7):1117-1124.

30. Bouma MG, Jeunhomme TM, Boyle DL, et al. Adenosine inhibits neutrophil degranulation in activated human whole blood: involvement of adenosine A2 and A3 receptors. J Immunol. 1997;158(11): 5400-5408.

31. Shecterle LM, St Cyr JA. Dermal benefits of topical D-ribose. Clin Cosmet Investig Dermatol. 2009;2:151-152.

32. Borel M, Calmon E, Bezivin C, Pletsch S, St Cyr JA. D-ribose enhances basal and mitochrondrial respiratory rates in human dermal fibroblasts. FASEB J. 2007;21(6):A835.

33. Kawashima M, Mizuno A, Murata Y. Improvement of hyperpigmentation based on accelerated epidermal turnover: clinical effects of disodium adenosine monophosphate in patients with melasma. Jpn J Clin Dermatol. 2008;62:250-257.

34. Furukawa F, Kanehara S, Harano F, et al. Effects of adenosine 5'-monophosphate on epidermal turnover. Arch Dermatol Res. 2008;300(9):485-493.

35. Ando H, Matsui MS, Ichihashi M. Quasi-drugs developed in Japan for the prevention or treatment of hyperpigmentary disorders. Int J Mol Sci. 2010;11:2566-2575.

36. Burnstock G, Knight GE, Greig AV. Purinergic signaling in healthy and diseased skin. J Invest Dermatol. 2012;132(3 Pt 1):526-546.

37. Cronstein BM. Adenosine receptors and wound healing, revised. Scientific WorldJournal. 2006;6:984-991.

38. Thibodeau A. Protecting the skin from environmental stresses with an exopolysaccharide formulation. Cosmet Toiletries. 2005;120(12): 81-89.

39. Nusgens BV, Humbert P, Rougier A, et al. Topically applied vitamin C enhances the mRNA level of collagens I and III, their processing enzymes and tissue inhibitor of matrix metalloproteinase 1 in the human dermis. J Invest Dermatol. 2001;116(6):853-859.
40. Kameyama K, Sakai C, Kondoh S, et al. Inhibitory effect of magnesium L-ascorbyl-2-phosphate (VC PMG) on melanogenesis in vitro and in vivo. J Am Acad Dermatol. 1996;34(1):29-33.

41. Sauermann K, Jaspers S, Koop U, Wenck H. Topically applied vitamin C increases the density of dermal papillae in aged human skin. $B M C$ Dermatol. 2004;4(1):13.

42. Boyera N, Galey I, Bernard BA. Effect of vitamin C and its derivatives on collagen synthesis and cross-attachment linking by normal human fibroblasts. Int J Cosmet Sci. 1998;20(3):151-158.

43. Xie Y, Chen X. Structures required of polyphenols for inhibiting advanced glycation end products formation. Curr Drug Metab. 2013; 14(4):414-431.

44. Caengprasath N, Ngamukote S, Mäkynen K, Adisakwattana S. The protective effects of pomelo extract (Citrus grandis L. Osbeck) against fructose-mediated protein oxidation and glycation. EXCLI J 2013;12:491-502.

45. Leite Gde O, Leite LH, Sampaio Rde S, et al. (-)- $\alpha$-Bisabolol attenuates visceral nociception and inflammation in mice. Fitoterapia. 2011;82(2):208-211.

46. Kamatou GPP, Viljoen AM. A review of the application and pharmacological properties of $\alpha$-bisabolol and $\alpha$-bisabolol-rich oils. J Am Oil Chem Soc. 2010;87:1-7.

47. Mamalis A, Nguyen DH, Brody N, Jagdeo J. The active natural antioxidant properties of chamomile, milk thistle, and halophilic bacterial components in human skin in vitro. J Drugs Dermatol. 2013;12(7): 780-784.

48. Herrmann M, Meyer I, Joppe H, Vielhaber G. The Syngeristic Antiirritant Effects of (-)- $\alpha$-Bisabolol and Ginger. Cosmetics and Toiletries. 2007 December; 122(7).

49. Kim S, Lee J, Jung E, et al. Mechanisms of depigmentation by alphabisabolol. J Dermatol Sci. 2008;52(3):219-222.

50. Lee J, Jun H, Jung E, Ha J, Park D. Whitening effect of alpha-bisabolol in Asian women subjects. Int J Cosmet Sci. 2010;32(4):299-303.

51. Herman A, Herman AP. Caffeine's mechanisms of action and its cosmetic use. Skin Pharmacol Physiol. 2013;26(1):8-14.

52. Jagdeo J, Brody N. Complementary antioxidant function of caffeine and green tea polyphenols in normal human skin fibroblasts. $J$ Drugs Dermatol. 2011;10(7):753-761.

53. Dayan N, Sivalenka R, Chase J. Skin moisturization by hydrogenated polyisobutene - quantitative and visual evaluation. J Cosmet Sci. 2009;60(1):15-24.

54. Hexsel D, Zechmeister do Prado D, Rao J, Goldman MP. Topical management of cellulite. In: Goldman MP, Bacci PA, Leibaschoff G, Hexsel D, Angelinii F, editors. Cellulite: Pathophysiology and Treatment. New York: Taylor and Francis Group; 2006:159-170.

55. Nayak BS, Ramdeen R, Adogwa A, Ramsubhag A, Marshall JR. Wound-healing potential of an ethanol extract of Carica papaya (Caricaceae) seeds. Int Wound J. 2012;9(6):650-655.

56. Dayanand CD, Krishnamurthy N, Ashakiran S, Shashidhar KN. Carnitine: a novel health factor - an overview. Int J Pharm Biomed Res. 2011;2(2):79-89.

57. Karsidag T, Asensio JA, Kabukcuoglu F, Tuzun S. Preliminary study comparing the effects of locally and systemically applied L-carnitine on the healing of full-thickness skin defects. Scand J Surg. 2010;99(3):147-152.

58. Wallimann T, Tokarska-Schlattner M, Schlattne U. The creatine kinase system and pleiotropic effects of creatine. Amino Acids. 2011;40(5):1271-1296.

59. Osamu T, Akinori H. The efficacy of L-carnitine on topical application for dry skin. The development of new active ingredient for dry skin as quasi-drug. Fragr J. 2005;33(8):82-85.

60. Pillich RT, Scarsella G, Risuleo G. Reduction of apoptosis through the mitochondrial pathway by the administration of acetyl-L-carnitine to mouse fibroblasts in culture. Exp Cell Res. 2005;306(1):1-8.

61. Parameshwaraiah S, Shivakumar HG. Evaluation of topical formulations of aqueous extract of Centella asiatica on open wounds in rats. Indian J Exp Biol. 1998;36(6):569-572. 
62. Haftek M, Mac-Mary S, Le Bitoux MA, et al. Clinical, biometric and structural evaluation of the long-term effects of a topical treatment with ascorbic acid and madecassoside in photoaged human skin. Exp Dermatol. 2008;17(11):946-952.

63. Paolino D, Cosco D, Cilurzo F, et al. Improved in vitro and in vivo collagen biosynthesis by asiaticoside-loaded ultradeformable vesicles. J Control Release. 2012;162(1):143-151.

64. Shukla A, Rasik AM, Dhawan BN. Asiaticoside-induced elevation of antioxidant levels in healing wounds. Phytother Res. 1999;13(1): 50-54.

65. Garcia C, Stoltz C, inventors; SEPPIC, assignee. Use of quinoa extract as cosmetic and pharmaceutic slimming agent and/or as an agent preventing the formation of new fats in the human body. United States patent US 20100061945 A1. March 11, 2010.

66. Greenway FL, Bray GA, Heber D. Topical fat reduction. Obes Res. 1995;3 Suppl 4:561S-568S.

67. Passeron T, Namiki T, Passeron HJ, Le Pape E, Hearing VJ. Forskolin protects keratinocytes from UVB-induced apoptosis and increases DNA repair independent of its effects on melanogenesis. J Invest Dermatol. 2009;129(1):162-166.

68. Peirano RI, Achterberg V, Düsing HJ, et al. Dermal penetration of creatine from a face-care formulation containing creatine, guarana and glycerol is linked to effective antiwrinkle and antisagging efficacy in male subjects. J Cosmet Dermatol. 2011;10(4):273-281.

69. Lenz H, Schmidt M, Welge V, et al. The creatine kinase system in human skin: Protective effects of creatine against oxidative and UV damage in vitro and in vivo. J Invest Dermatol. 2005;124(2):443-452.

70. Knott A, Koop U, Mielke H, et al. A novel treatment option for photoaged skin. J Cosmet Dermatol. 2008;7(1):15-22.

71. Blatt T, Lenz H, Koop U, et al. Stimulation of skin's energy metabolism provides multiple benefits for mature human skin. Biofactors. 2005;25(1-4):179-185.

72. Kobayashi A, Shibazaki T. Manufacture and physiological activities of hydroxyproline. Fragr J. 2003;31(3):37-43.

73. McNulty AK, Rhodes TJ, inventors; McNulty AK, Rhodes TJ, assignees. Protease inhibitor compositions for prevention and treatment of skin conditions. United States patent US 20050048105 A1. March 3, 2005.

74. Nagao S, Uehara K. Application to the cosmetics of amino acid derivatives. Fragr J. 2004;32(7):51-58.

75. Hashizume E, Nakano T, Kamimura A, Morishita K. Topical effects of N-acetyl-L-hydroxyproline on ceramide synthesis and alleviation of pruritus. Clin Cosmet Investig Dermatol. 2013;6:43-49.

76. Lintner K, inventor; Sederma, assignee. Cosmetic or dermopharmaceutical compositions which are used to reduce bags and circles under the eyes. European patent EP 1474100 B1. August 14, 2013.

77. Facino RM, Carini M, Stefani R, Aldini G, Saibene L. Anti-elastase and anti-hyaluronidase activities of saponins and sapogenins from Hedera helix, Aesculus hippocastanum, and Ruscus aculeatus: factors contributing to their efficacy in the treatment of venous insufficiency. Arch Pharm (Weinheim). 1995;328(10):720-724.

78. Luzzi R, Feragalli B, Belcaro G, et al. Aescin: microcirculatory activity. Effects of accessory components on clinical and microcirculatory efficacy. Panminerva Med. 2011;53(3 Suppl 1):51-55.

79. Hexsel D, Orlandi C, Zechmeister do Prado D. Botanical extracts used in the treatment of cellulite. Dermatol Surg. 2005;31(7 Pt 2):866-872.

80. Fujimura T, Tsukahara K, Moriwaki S, Hotta M, Kitahara T, Takema Y. A horse chestnut extract, which induces contraction forces in fibroblasts, is a potent anti-aging ingredient. $J$ Cosmet Sci. 2006;57(5):369-376.

81. Rosenthal RA, Fish B, Hill RP, et al. Salen Mn complexes mitigate radiation injury in normal tissues. Anticancer Agents Med Chem. 2011;11(4):359-372.

82. Declercq L, Sente I, Hellemans L, Corstjens H, Maes D. Use of the synthetic superoxide dismutase/catalase mimetic EUK-134 to compensate for seasonal antioxidant deficiency by reducing pre-existing lipid peroxides at the human skin surface. Int J Cosmet Sci. 2004;26(5): 255-263.
83. Decraene D, Smaers K, Gan D, et al. A synthetic superoxide dismutase/ catalase mimetic (EUK-134) inhibits membrane-damage-induced activation of mitogen-activated protein kinase pathways and reduces p53 accumulation in ultraviolet B-exposed primary human keratinocytes. J Invest Dermatol. 2004;122(2):484-491.

84. Thibodeau A. The crucial role of metalloproteinase inhibitors and regenerating antioxidants in the age-related alterations of the skin. SOFW J. 2005;131(4):10-20.

85. Paromov V, Kumari S, Brannon M, et al. Protective effect of liposomeencapsulated glutathione in a human epidermal model exposed to a mustard gas analog. J Toxicol. 2011;2011:109516.

86. Villarama CD, Maibach HI. Glutathione as a depigmenting agent: an overview. Int J Cosmet Sci. 2005;27(3):147-153.

87. Fluhr JW, Darlenski R, Surber C. Glycerol and the skin: holistic approach to its origin and functions. Br J Dermatol. 2008;159(1):23-34.

88. Draelos ZD. Active agents in common skin care products. Plast Reconstr Surg. 2010;125(2):719-724.

89. Moon MH, Jeong JK, Lee YJ, et al. 18ß-Glycyrrhetinic acid inhibits adipogenic differentiation and stimulates lipolysis. Biochem Biophys Res Commun. 2012;420(4):805-810.

90. Armanini D, Nacamulli D, Francini-Pesenti F, Battagin G, Ragazzi E, Fiore C. Glycyrrhetinic acid, the active principle of licorice, can reduce the thickness of subcutaneous thigh fat through topical application. Steroids. 2005;70(8):538-542.

91. Afnan Q, Adil MD, Nissar-U1A, et al. Glycyrrhizic acid (GA), a triterpenoid saponins glycoside alleviates ultraviolet-B irradiationinduced photoaging in human dermal fibroblasts. Phytomedicine. 2012;19(7):658-664.

92. Asl MN, Hosseinzadeh H. Review of pharmacological effects of Glycyrrhiza sp and its bioactive compounds. Phytother Res. 2008;22(6):709-724.

93. Graf J. Herbal anti-inflammatory agents for skin disease. Skin Therapy Lett. 2000;5(4):3-5.

94. Saeedi M, Morteza-Semnani K, Ghoreishi MR. The treatment of atopic dermatitis with licorice gel. J Dermatolog Treat. 2003;14(3):153-157.

95. Cohen D, Heidary N. Treatment of irritant and allergic contact dermatitis. Dermatol Ther. 2004;17(4):334-340.

96. Callender VD, St Surin-Lord S, Davis EC, Maclin M. Postinflammatory hyperpigmentation: etiologic and therapeutic considerations. Am JClin Dermatol. 2011;12(2):87-99.

97. Goldman MP, Bacci PA, Leibaschoff G, Hexsel D, Angelinii F, editors. Cellulite: Pathophysiology and Treatment. New York: Taylor and Francis Group; 2006.

98. Rai A. The antiinflammatory and antiarthritic properties of ethanol extract of Hedera helix. Indian J Pharm Sci. 2013;75(1):99-102.

99. Gülçin I, Mshvildadze V, Gepdiremen A, Elias R. Antioxidant activity of saponins isolated from ivy: alpha hederin, hederasaponin-C, hederacolchiside-E and hederacolchiside-F. Planta Med. 2004;70(6): 561-563.

100. Koyuncu H, Berkarda B, Baykut F, et al. Preventive effect of hesperidin against inflammation in CD-1 mouse skin caused by tumor promoter. Anticancer Res. 1999;19(4B):3237-3241.

101. Silva AR, Menezes PF, Martinello T, Novakovich GF, Praes CE, Feferman IH. Antioxidant kinetics of plant-derived substances and extracts. Int J Cosmet Sci. 2010;32(1):73-80.

102. Hou M, Man M, Man W, et al. Topical hesperidin improves epidermal permeability barrier function and epidermal differentiation in normal murine skin. Exp Dermatol. 2012;21(5):337-340.

103. Jin S, Zhou B, Luo D. Hesperidin promotes cyclobutane pyrimidine dimer repair in UVB-exposed mice epidermis. Ir J Med Sci. 2011;180(3):709-714.

104. Zhu W, Gao J. The use of botanical extracts as topical skin-lightening agents for the improvement of skin pigmentation disorders. $J$ Investig Dermatol Symp Proc. 2008;13(1):20-24.

105. Li D, Mitsuhashi S, Ubukata M. Protective effects of hesperidin derivatives and their stereoisomers against advanced glycation end-products formation. Pharm Biol. 2012;50(12):1531-1535. 
106. Leite e Silva VR, Schulman MA, Ferelli C, et al. Hydrating effects of moisturizer active compounds incorporated into hydrogels: in vivo assessment and comparison between devices. J Cosmet Dermatol. 2009;8(1):32-39.

107. Lu M, Duggan M, Menon G, Theophilus E, Dokka S, Wang H, inventors; Avon Prod Inc, assignee. Topical cosmetic composition with skin rejuvenation benefits. European patent EP 1441686 B1. July 2, 2008.

108. Agyare C, Dwobeng AS, Agyepong N, et al. Antimicrobial, antioxidant, and wound healing properties of Kigelia africana (Lam) Beneth and Strophanthus hispidus DC. Adv Pharmacol Sci. 2013;2013:692613.

109. Picerno P, Autore G, Marzocco S, Meloni M, Sanogo R, Aquino RP. Anti-inflammatory activity of verminoside from Kigelia africana and evaluation of cutaneous irritation in cell cultures and reconstituted human epidermis. J Nat Prod. 2005;68(11):1610-1614.

110. Oyedeji FO, Bankole-Ojo OS. Quantitative evaluation of the antipsoriatic activity of sausage tree (Kigelia africana). AJPAC. 2012;6(13): 214-218.

111. Morvan PY, L Pentecouteau L, Offredo H, Vallée R. Anti-ageing and slimming potential of a lotus maritimus extract via its effect on mitochondrial sirtuins on human skin cells. Proceedings of the 26th IFSCC Congress; September 20-23, 2010; Buenos-Aires, Argentina.

112. Paufique J, inventor; SILAB, assignee. Use of active ingredient comprising combination of active ingredient obtained from medicago sativa and active ingredient from Lupinus albus, to prepare cosmetic and/or dermopharmaceutical composition to fight against bags under the eyes. French patent FR 2921836-A1. October 5, 2007.

113. Gaultier F, Foucault-Bertaud A, Lamy E, et al. Effects of a vegetable extract from Lupinus albus (LU105) on the production of matrix metalloproteinases (MMP1, MMP2, MMP9) and tissue inhibitor of metalloproteinases (TIMP1, TIMP2) by human gingival fibroblasts in culture. Clin Oral Investig. 2003;7(4):198-205.

114. Siger A, Czubinski J, Kachlicki P, Dwiecki K, Lampart-Szczapa E, Nogala-Kalucka M. Antioxidant activity and phenolic content in three Lupin species. J Food Comp Anal. 2012;25(2):190-197.

115. Paufique J, inventor; SILAB, assignee. Active ingredient obtained from powdered Medicago sativa seeds. European patent EU 1559417A1. August 3, 2005.

116. Paufique J, inventor; SILAB, assignee. Method for obtaining a slimming cosmetic active agent, active ingredient obtained and composition including same. World patent WO2008087361 A2. July 24, 2008.

117. Choulot JC, inventor; Caster, assignee. Composition topique à visée amincissante. European patent EP 2604317 A1. June 19, 2013.

118. Huang B, Zhu L, Liu S, et al. In vitro and in vivo evaluation of inhibition activity of lotus (Nelumbo nucifera Gaertn.) leaves against ultraviolet B-induced phototoxicity. J Photochem Photobiol B. 2013;121: $1-5$.

119. Lupo MP. Peptides for facial skin aging. In: Shiffman MA, Mirrafati SJ, Lam SM, Cueteaux CG, editors. Simplified Facial Rejuvenation, Part III. Berlin: Springer Berlin Heidelberg; 2008:79-81.

120. Maquart FX, Pickart L, Laurent M, Gillery P, Monboisse JC, Borel JP. Stimulation of collagen synthesis in fibroblast cultures by the tripeptide-copper complex glycyl-L-histidyl-Llysine-Cu2+. FEBS Lett. 1988;238(2):343-346.

121. Maquart FX, Bellon G, Pasco S, Monboisse JC. Matrikines in the regulation of extracellular matrix degradation. Biochimie. 2005;87(3-4): 353-360.

122. Pickart L. The human tri-peptide GHK and tissue remodeling. J Biomater Sci Polym Ed. 2008;19(8):969-988.

123. Choi HR, Kang YA, Ryoo SJ, et al. Stem cell recovering effect of copper-free GHK in skin. J Pept Sci. 2012;18(11):685-690.

124. Mas-Chamberlin C, Mondon P, Lamy F, Peschard O, Lintner K. Reduction of hair-loss: matrikines and plant molecules to the rescue. In: Krisdaphong P, editor. Proceedings of the 7th Scientific Conference of the Asian Society of Cosmetic Chemists (ASCS): Toward a New Horizon: Uniting Cosmetic Science with Oriental Wisdom; March 7-9, 2005; Bangkok, Thailand: Society of Cosmetic Chemists of Thailand; 2005 .
125. Lintner K, inventor; Sederma, assignee. Utilisation cosmétique ou pharmaceutique de peptides pour la régulation des dysfonctionnements immunologiques et dans l'inflammation cutanée. World patent WO2000043417 A1. July 27, 2000.

126. dal Farra C, Domloge N, Botto JM, inventors; ISP, assignee. Dermatological and/or cosmetic composition containing polypeptides. United States patent US 20080171076 A1. July 17, 2008.

127. dal Farra C, Berghi A, Oberto G, Domloge N. Significant in vivo slimming properties observed in new UCP-like peptide. $J$ Am Acad Dermatol. 2007;56(2):AB88, P1015.

128. Rios L, Delattre C, Chaisemartin L, Favre-Mercuret M, Berthon JY. A new generation of slimming products. SOFW J. 2012;138(11): $1-11$.

129. Rios L, Delattre C, Patriarca P, Favre-Mercuret M, Berthon JY. A polyglucuronic acid to target the fiaf adipokine for slimming effects. Cosmet Toiletries. 2011;126(3):196-206.

130. Darlenski R, Surber C, Fluhr JW. Topical retinoids in the management of photodamaged skin: from theory to evidence-based practical approach. Br J Dermatol. 2010;163(6):1157-1165.

131. Kligman AM, Dogadkina D, Lavker RM. Effects of topical tretinoin on non-sun-exposed protected skin of the elderly. J Am Acad Dermatol. 1993;29(1):25-33.

132. Varani J, Warner RL, Gharaee-Kermani M, et al. Vitamin A antagonizes decreased cell growth and elevated collagen-degrading matrix metalloproteinases and stimulates collagen accumulation in naturally aged human skin. J Invest Dermatol. 2000;114(3):480-486.

133. Kang S. The mechanism of action of topical retinoids. Cutis. 2005; 75(Suppl 2):10-13.

134. Wolf JE Jr. Potential anti-inflammatory effects of topical retinoids and retinoid analogues. Adv Ther. 2002;19(3):109-118.

135. Bellemère G, Von Stetten O, Oddos T. Retinoic acid increases aquaporin 3 expression in normal human skin. $J$ Invest Dermatol. 2008;128(3):542-548.

136. Murphy GF, Katz S, Kligman AM. Topical tretinoin replenishes CD1a-positive epidermal Langerhans cells in chronically photodamaged human skin. J Cutan Pathol. 1998;25(1):30-34.

137. Ortonne JP. Retinoid therapy of pigmentary disorders. Dermatol Ther 2006;19(5):280-288

138. Bellemère G, Stamatas GN, Bruère V, Bertin C, Issachar N, Oddos T. Antiaging action of retinol: from molecular to clinical. Skin Pharmacol Physiol. 2009;22(4):200-209.

139. Sabancilar E, Aydin F, Bek Y, et al. Treatment of melasma with a depigmentation cream determined with colorimetry. $J$ Cosmet Laser Ther. 2011;13(5):255-259.

140. Merinville E, Byrne AJ, Visdal-Johnsen L, et al. Clinical evaluation of a dioic acid-based formulation on facial skin in an Indian population. Int J Cosmet Sci. 2012;34(6):575-581.

141. Maswadeh HM, Semreen MH, Naddaf AR. Anti-inflammatory activity of Achillea and Ruscus topical gel on carrageenan-induced paw edema in rats. Acta Pol Pharm. 2006;63(4):277-280.

142. Sharma S, Kaur IP. Development and evaluation of sesamol as an antiaging agent. Int J Dermatol. 2006;45(3):200-208.

143. Hu Q, Xu J, Chen S, Yang F. Antioxidant activity of extracts of black sesame seed (Sesamum indicum L.) by supercritical carbon dioxide extraction. J Agric Food Chem. 2004;52(4):943-947.

144. Suja KP, Jayalekshmy A, Arumughan C. Free radical scavenging behavior of antioxidant compounds of sesame (Sesamum indicum L.) in DPPH(*) system. J Agric Food Chem. 2004;52(4):912-915.

145. Kiran K, Asad M. Wound healing activity of Sesamum indicum L seed and oil in rats. Indian J Exp Biol. 2008;46(11):777-782.

146. Schlesinger TE, Powell CR. Efficacy and tolerability of low molecular weight hyaluronic acid sodium salt $0.2 \%$ cream in rosacea. $J$ Drugs Dermatol. 2013;12(6):664-667.

147. Pavicic T, Gauglitz GG, Lersch P, et al. Efficacy of cream-based novel formulations of hyaluronic acid of different molecular weights in anti-wrinkle treatment. J Drugs Dermatol. 2011;10(9): 990-1000. 
148. Gariboldi S, Palazzo M, Zanobbio L, et al. Low molecular weight hyaluronic acid increases the self-defense of skin epithelium by induction of beta-defensin 2 via TLR2 and TLR4. J Immunol. 2008;181(3): 2103-2110.

149. Draelos ZD. New treatments for restoring impaired epidermal barrier permeability: skin barrier repair creams. Clin Dermatol. 2012;30(3): $345-348$.

150. Mummert ME. Immunologic roles of hyaluronan. Immunol Res. 2005;31(3):189-206.

151. Chen WY, Abatangelo G. Functions of hyaluronan in wound repair. Wound Repair Regen. 1999;7(2):79-89.

152. Merinville E, Byrne AJ, Rawlings AV, Muggleton AJ, Laloeuf AC. Three clinical studies showing the anti-aging benefits of sodium salicylate in human skin. J Cosmet Dermatol. 2010;(3):174-184.

153. Weimar V. Polymorphonuclear invasion of wounded corneas; inhibition by topically applied sodium salicylate and soybean trypsin inhibitor. J Exp Med. 1957;105(2):141-152.

154. Bair WB 3rd, Hart N, Einspahr J, et al. Inhibitory effects of sodium salicylate and acetylsalicylic acid on UVB-induced mouse skin carcinogenesis. Cancer Epidemiol Biomarkers Prev. 2002;11(12): 1645-1652.

155. Lin AN, Nakatsui T. Salicylic acid revisited. Int J Dermatol. 1998; 37(5):335-342.

156. Huang ZR, Lin YK, Fang JY. Biological and pharmacological activities of squalene and related compounds: potential uses in cosmetic dermatology. Molecules. 2009;14(1):540-554.

157. Wołosik K, Knaś M, Zalewska A, Niczyporuk M, Przystupa AW. The importance and perspective of plant-based squalene in cosmetology. J Cosmet Sci. 2013;(1):59-66.

158. Kim SK, Bhatnagar I. Physical, chemical, and biological properties of wonder kelp-Laminaria. Adv Food Nutr Res. 2011;64:85-96.

159. Anton JG, Puche JC, Valles AG, Passerini E, inventors; Lipotec SA, assignee. Composition for the prevention and treatment of cellulitis. United States patent US 20070031516 A1. February 8, 2007.

160. Cals-Grierson MM. Modulation of activity of the adipocyte aquaglyceroporin channel by plant extracts. Int J Cosmet Sci. 2007; 29(1):7-14.

161. Mitani H, Ryu A, Suzuki T, Yamashita M, Arakane K, Koide C. Topical application of plant extracts containing xanthine derivatives can prevent UV-induced wrinkle formation in hairless mice. Photodermatol Photoimmunol Photomed. 2007;23(2-3):86-94.

162. Ramiro E, Franch A, Castellote C, et al. Flavonoids from Theobroma cacao down-regulate inflammatory mediators. J Agric Food Chem. 2005;53(22):8506-8511.

163. Sanbongi C, Osakabe N, Natsume M, Takizawa T, Gomi S, Osawa T. Antioxidative polyphenols isolated from Theobroma cacao. J Agric Food Chem. 1998;46(2):454-457.

164. Gorouhi F, Maibach HI. Role of topical peptides in preventing or treating aged skin. Int J Cosmet Sci. 2009;31(5):327-345.
165. Gruchlik A, Jurzak M, Chodurek E, Dzierzewicz Z. Effect of Gly-GlyHis, Gly-His-Lys and their copper complexes on TNF-alpha-dependent IL-6 secretion in normal human dermal fibroblasts. Acta Pol Pharm. 2012;69(6):1303-1306.

166. Hussain M, Goldberg DJ. Topical manganese peptide in the treatment of photodamaged skin. J Cosmet Laser Ther. 2007;9(4):232-236.

167. Kang YA, Choi HR, Na JI, et al. Copper-GHK increases integrin expression and p63 positivity by keratinocytes. Arch Dermatol Res. 2009;301(4):301-306.

168. Zhang L, Falla TJ. Cosmeceuticals and peptides. Clin Dermatol. 2009;27(5):485-494.

169. Thiele JJ, Ekanayake-Mudiyanselage S. Vitamin E in human skin: organ-specific physiology and considerations for its use in dermatology. Mol Aspects Med. 2007;28(5-6):646-667.

170. Kato E, Takahashi N. Improvement by sodium dl- $\alpha$-tocopheryl-6-Ophosphate treatment of moisture-retaining ability in stratum corneum through increased ceramide levels. Bioorg Med Chem. 2012;20(12): 3837-3842.

171. De Pascale MC, Bassi AM, Patrone V, Villacorta L, Azzi A, Zingg JM. Increased expression of transglutaminase-1 and PPARgamma after vitamin E treatment in human keratinocytes. Arch Biochem Biophys. 2006;447(2):97-106.

172. Jain SK, Palmer M. The effect of oxygen radicals metabolites and vitamin E on glycosylation of proteins. Free Radic Biol Med. 1997;22(4):593-596.

173. Muta-Takada K, Terada T, Yamanishi H, et al. Coenzyme Q10 protects against oxidative stress-induced cell death and enhances the synthesis of basement membrane components in dermal and epidermal cells. Biofactors. 2009;35(5):435-441.

174. Inui M, Ooe M, Fujii K, Matsunaka H, Yoshida M, Ichihashi M. Mechanisms of inhibitory effects of CoQ10 on UVB-induced wrinkle formation in vitro and in vivo. Biofactors. 2008;32(1-4):237-243.

175. Hoppe U, Bergemann J, Diembeck W, et al. Coenzyme Q10, a cutaneous antioxidant and energizer. Biofactors. 1999;9(2-4):371-378.

176. Prahl S, Kueper T, Biernoth T, et al. Aging skin is functionally anaerobic: importance of coenzyme Q10 for anti aging skin care. Biofactors. 2008;32(1-4):245-255.

177. Grether-Beck S, Felsner I, Brenden H, et al. Urea uptake enhances barrier function and antimicrobial defense in humans by regulating epidermal gene expression. J Invest Dermatol. 2012;132(6):1561-1572.

178. Hagemann I, Proksch E. Topical treatment by urea reduces epidermal hyperproliferation and induces differentiation in psoriasis. Acta Derm Venereol. 1996;76(5):353-356.

179. Zhu K, Zhou H, Qian H. Antioxidant and free radical-scavenging activities of wheat germ protein hydrolysates (WGPH) prepared with alcalase. Process Biochemistry. 2006;41(6):1296-1302.

180. Saraf S, Sahu S, Kaur CD, Saraf S. Comparative measurement of hydration effects of herbal moisturizers. Pharmacognosy Res. 2010;2(3):146-151.
Clinical, Cosmetic and Investigational Dermatology

\section{Publish your work in this journal}

Clinical, Cosmetic and Investigational Dermatology is an international, peer-reviewed, open access, online journal that focuses on the latest clinical and experimental research in all aspects of skin disease and cosmetic interventions. All areas of dermatology will be covered; contributions will be welcomed from all clinicians and

\section{Dovepress}

basic science researchers globally. This journal is indexed on CAS The manuscript management system is completely online and includes a very quick and fair peer-review system, which is all easy to use. Visit http://www.dovepress.com/testimonials.php to read real quotes from published authors. 